\title{
Article
}

\section{Chromophore Distortions in Photointermediates of Proteorhodopsin visualized by DNP-enhanced solid-state NMR}

Michaela Mehler, Carl Elias Eckert, Alexander J. Leeder, Jagdeep Kaur, Tobias Fischer, Nina Kubatova, Lynda J. Brown, Richard C. D. Brown, Johanna Becker-Baldus, Josef Wachtveitl, and Clemens Glaubitz J. Am. Chem. Soc., Just Accepted Manuscript • DOI: 10.1021/jacs.7b05061 • Publication Date (Web): 13 Oct 2017

Downloaded from http://pubs.acs.org on October 31, 2017

\section{Just Accepted}

"Just Accepted" manuscripts have been peer-reviewed and accepted for publication. They are posted online prior to technical editing, formatting for publication and author proofing. The American Chemical Society provides "Just Accepted" as a free service to the research community to expedite the dissemination of scientific material as soon as possible after acceptance. "Just Accepted" manuscripts appear in full in PDF format accompanied by an HTML abstract. "Just Accepted" manuscripts have been fully peer reviewed, but should not be considered the official version of record. They are accessible to all readers and citable by the Digital Object Identifier (DOI®). "Just Accepted" is an optional service offered to authors. Therefore, the "Just Accepted" Web site may not include all articles that will be published in the journal. After a manuscript is technically edited and formatted, it will be removed from the "Just Accepted" Web site and published as an ASAP article. Note that technical editing may introduce minor changes to the manuscript text and/or graphics which could affect content, and all legal disclaimers and ethical guidelines that apply to the journal pertain. ACS cannot be held responsible for errors or consequences arising from the use of information contained in these "Just Accepted" manuscripts. 
1

2

3

4

5

6

7

8

9

10

11

12

13

14

15

16

17

18

19

20

21

22

23

24

25

26

27

28

29

30

31

32

33

34

35

36

37

38

39

40

41

42

43

44

45

46

47

48

49

50

51

52

53

54

55

56

57

58

59

60

\section{Chromophore Distortions in Photointermediates of Proteorhodopsin visualized by} DNP-enhanced solid-state NMR

Michaela Mehler ${ }^{1}$, Carl Elias Eckert ${ }^{2}$, Alexander J. Leeder ${ }^{3}$, Jagdeep Kaur ${ }^{1}$, Tobias Fischer ${ }^{2}$, Nina Kubatova ${ }^{1}$, Lynda J. Brown ${ }^{3}$, Richard C. D. Brown ${ }^{3}$, Johanna Becker-Baldus ${ }^{1}$, Josef Wachtveitl ${ }^{2} \&$ Clemens Glaubitz ${ }^{1^{*}}$

(1) Institute for Biophysical Chemistry \& Centre for Biomolecular Magnetic Resonance, Goethe-University Frankfurt, Germany

(2) Institute for Physical and Theoretical Chemistry, Goethe-University Frankfurt, Germany

(3) Department of Chemistry, University of Southampton, Southampton, United Kingdom

(*) Email: glaubitz@em.uni-frankfurt.de

Institute of Biophysical Chemistry

Goethe University Frankfurt

Max-von-Laue-Str. 9

60438 Frankfurt am Main

Germany

Tel.: +49-69-798-29927

Fax.: +49-69-798-29929 


\section{Abstract}

Proteorhodopsin (PR) is the most abundant retinal protein on earth and functions as a lightdriven proton pump. Despite of extensive efforts, structural data for PR photointermediate states have not been obtained. Based on DNP-enhanced solid-state NMR, we were able to analyze the retinal polyene chain between positions $\mathrm{C} 10$ and $\mathrm{C} 15$ as well as the Schiff base nitrogen in the ground state in comparison to light induced, cryo-trapped K- and M-states. A high M-state population could be achieved by preventing reprotonation of the Schiff base through a mutation of the primary proton donor (E108Q). Our data reveal unexpected large and alternating ${ }^{13} \mathrm{C}$ chemical shift changes in the K-state propagating away from the Schiff base along the polyene chain. Furthermore, two different M-states have been observed reflecting the Schiff base reorientation after the de-protonation step. Our study provides novel insight into the photocycle of PR and also demonstrates the power of DNP-enhanced solid-state NMR to bridge the gap between functional and structural data and models.

\section{Keywords}

Membrane proteins, proteorhodopsin, photocycle, solid-state NMR, DNP, flash photolysis 


\section{Introduction}

Rhodopsins are found in all phyla of life and represent the most abundant phototrophic systems. ${ }^{1-4}$ By far the most abundant family members belong to the proteorhodopsins (PRs), which provided the first evidence for a bacterial retinal-based photoreceptor. ${ }^{1}$ Blue and green light absorbing subfamilies have been found. ${ }^{5}$ Their identification through metagenomic screens of uncultured sea samples lead to many hundreds of PR-like sequences distributed in numerous microorganisms from different geographic areas. ${ }^{6-8}$ Their prevalent occurrence in microbial communities in the ocean's photic zone and their ability to act as light-driven proton pumps, which creates a transmembrane electrochemical gradient, makes retinalbased phototrophy a very important bioenergetic factor in marine ecosystems during nutrient deficient periods. ${ }^{9,10}$ These studies also triggered the discovery of new rhodopsins and helped to expand knowledge of their spectrum of functions and distribution.

PR features the typical heptahelical transmembrane bundle with a retinal chromophore covalently bound to Lys231 and is a DTE-motif ion pump with the primary proton acceptor Asp97 and the proton donor Glu108. ${ }^{11-13}$ Furthermore Asp227 and Arg94 form together with the proton acceptor the Schiff base's counter-ion complex. Glu142 is proposed to be involved in proton release. ${ }^{14}$ In addition, proton-pumping efficiency is $\mathrm{pH}$ regulated due to the high $\mathrm{pK}_{\mathrm{a}}$ of Asp97, which is close to the environmental $\mathrm{pH}$. In contrast to other microbial rhodopsins, PR forms pentameric complexes supportive of its function. ${ }^{14-16}$ In order to perform proton transfer, PR undergoes a light induced photocycle with a number of characteristic intermediate states (Fig. 1A) ${ }^{6,10}$ Different from archaeal bacteriorhodopsin, only the all-trans retinal configuration is present in the dark and no dark-light adaptation step is observed. The photocycle is initiated by retinal isomerization from all-trans,15-anti to 13cis,15-anti around the $\mathrm{C} 13=\mathrm{C} 14$ double bond after which the K-state intermediate is formed. Subsequently, the protonated Schiff base (pSB) transfers its proton to Asp97 leading to the $M$-state with a reduced pi-electron delocalization, which yields a characteristic blue shift of the protein's absorption wavelength of $410 \mathrm{~nm}$. Next, the SB is reprotonated by the proton donor Glu108, during the N-state. From there, the retinal reisomerizes back to all-trans in the O-state. Finally, PR returns to the ground state with proton uptake by Glu108 (Fig. 1A, for a review see Bamann et al. ${ }^{17}$ ).

Although PR has been extensively studied by advanced biophysical methods ranging from time-resolved optical and vibrational spectroscopy, via liquid- and solid-state NMR to X-ray crystallography ${ }^{10,11,14,15,17-21}$, very little is known so far about conformational changes in the chromophore itself and the surrounding residues in the binding pocket during the photocycle. No structural data on photointermediates have been reported. Kinetic data for the photocycle are usually interpreted by analogy comparison with the less abundant, more exotic but 
extensively studied archaeal homologue bacteriorhodopsin (BR) from Halobacterium salinarium. ${ }^{10,22}$ However, the photocycle of the two proteins show clear differences, e.g. number and lifetime of the intermediate states and the retinal configuration in the dark state. Further differences include a highly conserved histidine residue associated with the active site of $\mathrm{PR}^{14,23,24}$, a different proton release group and the lack of the highly ordered water 402 between Schiff base and proton acceptor, which facilitates proton transfer in $\mathrm{BR}^{14}$. In addition, the discovery of many new rhodopsins has shown that the typical structural scaffold provides the basis for a great variety of functions, including cation and anion pumps, sensors and channels. These also manifest themselves in different optical properties, photocycle kinetics or populated intermediate states, which indicate important differences in their energy landscapes. These fine details need to be understood in order to comprehend how apparently similar molecular designs can yield such a variety of functions.

Solid-state NMR (ssNMR), especially in the form of magic angle sample spinning (MASNMR), is a powerful method for the investigation of membrane proteins and has been extensively applied to rhodopsins. ${ }^{15,18,25-34}$ The possibility to perform experiments on lightinduced and cryo-trapped photointermediate states directly within the lipid bilayers provides unique opportunities to bridge the gap between the spectroscopic characterization of the photocycle on the one hand and 3D structure analysis by crystallographic approaches on the other. ssNMR reports on the structure and the electronic environment of the chromophore and such data could be eventually linked to optical properties via quantum chemical approaches. However, only very few ssNMR studies have been reported on photointermediates due to the substantial challenges associated with the limited sensitivity of such experiments. Available data are restricted to bacteriorhodopsin, sensory and visual rhodopsin. ${ }^{29,34-37}$ Fortunately, the advent of dynamic nuclear polarization (DNP) enables new perspectives: The sensitivity of ssNMR can be boosted by orders of magnitude by magnetization transfer from suitable polarizing agents containing stable radicals to the nuclei of interest. ${ }^{38,39}$ For membrane protein samples, up to 50 - 60 fold sensitivity enhancements have been reported. Such an approach is of emerging importance for the detection of subpopulations of cryo-trapped photointermediate states as demonstrated for bacteriorhodopsin and channelrhodopsin-2. ${ }^{15,25}$

Here, we present DNP-enhanced MAS-NMR data on ${ }^{13} \mathrm{C}$-labelled retinal incorporated into ${ }^{15} \mathrm{~N}$-Lys-labelled green PR in the ground-, K- and M-states. In situ illumination protocols were established and the M-state population was enriched by additionally introducing the primary proton donor mutation $\mathrm{E} 108 \mathrm{Q}$, which does not cause any structural effects but elongates the photocycle by preventing the reprotonation of the Schiff base. In order to follow changes within the chromophore during the photocycle, the $\mathrm{HC} 14-\mathrm{C} 15 \mathrm{H}$ single-bond dihedral angle in 
14,15- ${ }^{13} \mathrm{C}_{2}$-E-retinal $\left({ }^{13} \mathrm{C}_{2}\right.$-retinal, Fig. $\left.1 \mathrm{C}\right)$ and ${ }^{13} \mathrm{C}$ chemical shifts in $10,11,12,13,14,15-{ }^{13} \mathrm{C}_{6^{-}}$ E-retinal $\left({ }^{13} \mathrm{C}_{6}\right.$-retinal, Fig. $\left.1 \mathrm{C}\right)$ were determined. Our data reveal the existence of two $\mathrm{M}$ states. Large chemical shift and dihedral angle changes were observed in the trapped photointermediates and reflect structural changes within chromophore and binding pocket. The response of the retinal polyene chain towards illumination during the first half of the PR photocycle is discussed in the context of time-resolved optical spectroscopy and in light of data from other microbial rhodopsins.

\section{Results}

\section{Cryo-Trapping of the K-Intermediate}

Proteorhodopsin was ${ }^{15} \mathrm{~N}$-Lys labeled and reconstituted with ${ }^{13} \mathrm{C}_{2}$-retinal or ${ }^{13} \mathrm{C}_{6}$-retinal (Fig. $1 \mathrm{C})$ so that retinal and Schiff base could be monitored in differently trapped states. All experiments were performed on proteoliposomes. DNP-enhanced, double-quantum filtered (DQF) ${ }^{13} \mathrm{C}$ spectra of ${ }^{13} \mathrm{C}_{2}$ - and ${ }^{13} \mathrm{C}_{6}$-retinal in the $\mathrm{PR}$ ground state are shown in Fig. 2. Using AMUPOL ${ }^{40}$ as polarizing agent, a 50 -fold signal enhancement for the ${ }^{13} \mathrm{C}$ retinal resonances could be achieved routinely (Fig. 2A). Chemical shifts were assigned based on doublequantum single-quantum (DQ-SQ) correlation experiments ${ }^{41}$ (Fig. 2B, Table 1), which were also verified by ${ }^{13} \mathrm{C}-{ }^{13} \mathrm{C}$ proton-driven spin diffusion (PDSD) correlation spectra (Fig. $6 \mathrm{~B}$ ).

In order to stabilize photocycle intermediates for structural analysis, a sample illumination protocol for cryo-trapping had to be established, which was adapted from procedures reported for bacteriorhodopsin ${ }^{25,27,30}$ and channelrhodopsin- $2^{31}$. Samples were illuminated directly within the MAS rotor under cryogenic conditions or at room temperature followed by fast freezing (thermal trapping) (Fig. 1B). In all cases, sample transparency was identified to be the most crucial parameter for achieving a high trapping efficiency as it determines the size of the light-activated protein population in the lipid bilayer entering the photocycle. ${ }^{31}$ Best light penetration was achieved by evenly spreading a thin film of proteorhodopsin liposomes at a high lipid : protein ratio of $2(\mathrm{w} / \mathrm{w})$ on the inner surface of a transparent sapphire MAS rotor. Such a setup results in a greatly reduced total protein sample (1-1.5 $\mathrm{mg})$ compared to a fully filled MAS rotor (12-20 mg), which makes the use of DNP-enhanced solid state NMR indispensable.

First, an efficient protocol for trapping the K-state was established by illuminating the sample directly within the DNP probe at about $100 \mathrm{~K}$ with a bright LED light source for $40 \mathrm{~min}$ (Fig. 1B). As a result, the DNP-enhanced DQF-spectra of ${ }^{13} \mathrm{C}_{2}$ or ${ }^{13} \mathrm{C}_{6}$-retinal show chemical shift changes as well as additional peaks (Fig. $3 \mathrm{~A}$ and $\mathrm{B}$ ). For example, in the ground state a chemical shift for $\mathrm{C} 14$ of $120.2 \mathrm{ppm}$ is observed, while under the described illumination a population at $117.7 \mathrm{ppm}$ arises $(3 \mathrm{~A}, \mathrm{~B})$. The ${ }^{15} \mathrm{~N}$ chemical shift of the pSB is not affected (Fig. 
$5 A)$. Assigning this thermally trapped state as the K-state is further confirmed by Cryo-UVVIS spectra recorded under similar conditions (Fig. 3C). The dark-light difference spectrum shows a decrease of the ground state absorption at $520 \mathrm{~nm}$, while a population at $580 \mathrm{~nm}$ arises, which is characteristic for the K-intermediate. As estimated from the NMR peak intensities, approx. $30 \%$ of the sample could be trapped into the K-state. This incomplete conversion is probably caused by equilibrium between $\mathrm{K}$ - and ground states, by the limited quantum yield and by a fraction of the sample, which was not illuminated due to non-ideal coupling of the light source into the DNP probe.

\section{Cryo-Trapping of the M-Intermediate}

Different possibilities exist - in principle - for trapping the M-state. One option would be thermal relaxation from the K-state, another would be to populate the M-state at higher temperature followed by thermal trapping. ${ }^{29}$ A suitable NMR-spectroscopic readout is provided by the ${ }^{15} \mathrm{~N}$ resonance of the Schiff base, which shifts by about $150 \mathrm{ppm}$ upon deprotonation in the M-state. ${ }^{29}$ Unfortunately, all attempts to convert wild type PR from its ground state into the M-state failed (Fig. S1). This is most likely due to the low population of the M-intermediate in the PR photocycle, which has been reported before ${ }^{11}$ and is also shown here by time-resolved absorption measurements (Fig. 4A). All expected photointermediates (K, M, N, O, and ground state) appear sequentially, but the population of the M-state is rather low (Fig. 4C). A potential solution to this problem is offered by preventing the decay of the M-state by replacing the primary proton donor E108 with the nontitratable amino acid glutamine. The overall photodynamics of $P R_{E 108 Q}$ is elongated and a significant M-state accumulation is observed (Fig. 4B). These time-resolved data are fitted with a global lifetime analysis (GLA) routine. Transient absorption changes at selected wavelengths together with their respective fits are shown for $P R$ and $P R_{E 108 Q}$ in Figs. $4 C$ and $D$, respectively. According to this data analysis, the PR photocycle is best described by six lifetimes: $5 \mu \mathrm{s}, 89 \mu \mathrm{s}, 0.6 \mathrm{~ms}, 3.4 \mathrm{~ms}, 24.5 \mathrm{~ms}$, and $100.2 \mathrm{~ms}$. The decay associated spectra (Fig. 4E) of the two fastest lifetimes describe the formation of the M-state and simultaneously the decay of the K-state. Subsequently, the M-state depopulates most likely with the two intermediate time constants of $0.6 \mathrm{~ms}$ and $24.5 \mathrm{~ms}$ resulting in the formation of the late intermediates. Finally, the photocycle completes with the depopulation of the $\mathrm{N}$ and $\mathrm{O}$ state and the recovery of the ground state described by the $24.5 \mathrm{~ms}$ and $100.2 \mathrm{~ms}$ time constants.

In contrast to wild type PR, the GLA analysis of $\mathrm{PR}_{\mathrm{E} 108 \mathrm{Q}}$ transient data results in four time constants. The respective decay associated spectra (Fig. 4F) reveal a bi-exponential M-state formation (70 $\mu \mathrm{s}$ and $1.2 \mathrm{~ms}$ ) and decay (210.3 ms and $2261.1 \mathrm{~ms})$. However, in contrast to the photodynamics of PR, the photocycle seems to end up without a detectable accumulation of the late intermediates. To verify this observation, an additional time-resolved absorption 
measurement with a temporal resolution of $1 \mathrm{~s}$ has been conducted (Fig. S2). Even $40 \mathrm{~s}$ after photoexcitation, there is no indication for the formation of the late intermediates. The high population and extended lifetime of the M-state in the $P R_{E 108 Q}$ mutant should enable efficient thermal trapping of this photointermediate, which was attempted here by illumination at room temperature followed by quick freezing and transfer into the DNP probe (Fig. 1B). Evidence for successful generation of the $\mathrm{M}$-state in $\mathrm{PR}_{\mathrm{E} 108 \mathrm{Q}}$ is provided by the detection of $a{ }^{15} \mathrm{~N}$ signal of the de-protonated Schiff base nitrogen at around 316 ppm (Fig. 5A). The ${ }^{15} \mathrm{~N}$ resonance at $181 \mathrm{ppm}$ indicates a remaining ground state population, which is probably caused by a combination of factors such as back relaxation during the transfer step into the DNP probe but also limited quantum yield and non-ideal light-coupling as mentioned above. Interestingly, an accumulation of the M-state via thermal relaxation from the K-intermediate was not possible in $\mathrm{PR}_{\mathrm{E} 108 \mathrm{Q}} \cdot{ }^{13} \mathrm{C}$-Spectra of ${ }^{13} \mathrm{C}_{2}$-retinal in the M-state are compared with the ground and $\mathrm{K}$-state in Fig. 5B. In the M-state, a new $\mathrm{C} 14$ resonance occurs, while the K-state appears completely depopulated (Fig. 5B). Both C14 and C15 resonances are broadened compared to the ground and K-states due to additional populations (see below).

Although the M-state can now be trapped, the question arises, whether the $\mathrm{E} 108 \mathrm{Q}$ mutation introduces any structural changes, which would make it more difficult to relate the obtained data to the characteristics of the M-state of wild type PR. Therefore, the ${ }^{13} \mathrm{C}$ chemical shifts of the retinal chromophore, which serve as a structural fingerprint of the active site, were compared for $\mathrm{PR}$ and $\mathrm{PR}_{\mathrm{E} 108 \mathrm{Q}}$ in both ground and K-states (Figs. S3, S4). All chemical shifts were found to be identical. The same observation was made for the ${ }^{15} \mathrm{~N}$ chemical shift of the pSB (Fig. 5A), which indicates that the E108Q mutation does not introduce any detectable structural changes at the chromophore. This observation fits well to the fact that position 108 is about $\sim 15 \AA$ away from the retinal binding pocket. Therefore, $P R_{E 108 Q}$ instead of wild type $\mathrm{PR}$ is used in the following for investigating the M-state by DNP-enhanced MAS-NMR.

\section{DNP-enhanced NMR characterization of $K$ - and M-intermediates}

Based on the trapping procedures described above, we were able to assign and compare ${ }^{13} \mathrm{C}$ chemical shifts of the retinal cofactor in the ground state with those observed in the K- and $\mathrm{M}$-state. The assignment was derived from single bond double quantum correlations in ${ }^{13} \mathrm{C}$ ${ }^{13} \mathrm{C} D Q-S Q{ }^{41}$ and cross peaks in $\mathrm{PDSD}^{42}$ correlation experiments on ${ }^{13} \mathrm{C}_{6}$-retinal in $\mathrm{PR}$ and $\mathrm{PR}_{\mathrm{E} 108 \mathrm{Q}}$ as shown in Fig. 6. As described above, all retinal resonances in the PR ground state could be assigned (Figs. 6A, B). A number of new resonances are observed. They correlate with each other and taken together describe a nearly complete retinal signal set, which we assign to the K-state (Figs. 6C, D). The reduced intensity of cross peaks with $\mathrm{C} 13$ is probably caused by the $\mathrm{C} 20$ methyl group relaxation under DNP conditions. The spectrum also contains signals from the residual ground state population. In the K-state the 
chromophore of PR undergoes a trans-to-cis isomerization around the $\mathrm{C} 13=\mathrm{C} 14$ double bond due to light absorption. This results in a significant de-shielding of $\mathrm{C} 11$ and $\mathrm{C} 13$ by -6.0 and $-3.1 \mathrm{ppm}$, while $\mathrm{C} 10, \mathrm{C} 12$ and $\mathrm{C} 14$ experience an additional shielding of $+2.4,6.9$ and $2.5 \mathrm{ppm}$, respectively (Table 1 ). Upon switching to the M-state new signals appear. They comprise two different sets of retinal signals with a difference observed for $\mathrm{C} 13$ and $\mathrm{C} 15$ indicating the existence of two $M$-states $M_{1}$ and $M_{2}$ (Figs. 6E, F; Table 1). The largest shielding effects are observed for C11 and C13, which change by 11.7 ppm and 19.1/ 21.6 ppm compared to the K-state. Resonances $\mathrm{C} 12$ and C14 are de-shielded by -3.9 and -6.4 ppm. For $\mathrm{C} 15$, one shielded (1.2 ppm) and one de-shielded (-3.1 ppm) population is detected. The observed ${ }^{13} \mathrm{C}$ chemical shift changes are illustrated in Fig. 7.

The existence of two M-states should be also reflected in the ${ }^{15} \mathrm{~N}$ resonance of the Schiff base nitrogen, but only one broad peak could be observed under our experimental conditions in the $1 \mathrm{D}{ }^{15} \mathrm{~N}$-spectrum shown in Fig. $5 \mathrm{~A}$. Therefore, ${ }^{15} \mathrm{~N}-{ }^{13} \mathrm{C}$ TEDOR dipolar through-space correlation spectra were recorded in order to verify that the populations identified in the ${ }^{13} \mathrm{C}$ spectra of the retinal co-factor correlate with a deprotonated ${ }^{15} \mathrm{~N}$ Schiff base resonance. Indeed, the data in Fig. 8 show that both ${ }^{13} \mathrm{C}$ resonances of $\mathrm{C} 15$ correlate with two slightly different ${ }^{15} \mathrm{~N}$ signals of the deprotonated Schiff base at 312 and $316 \mathrm{ppm}$, which overlapped in the ${ }^{15} \mathrm{~N} 1 \mathrm{D}$ spectrum (Fig. 5A). Furthermore, correlations between the protonated Schiff base nitrogen and $\mathrm{C} 13$ and the deprotonated Schiff base and C14 are detected. No correlation between $\mathrm{C} 13$ and the deprotonated Schiff base could be observed, since the longer distances result in a much smaller dipole coupling and therefore in a very small TEDOR signal.

The observation of two M-states could be a reflection of a reorientation of the Schiff base during de- and reprotonation. Such an event could cause an additional conformational change, e.g. an out-of-plane twist, at the end of the polyene chain. In order to test this hypothesis, we took advantage of the ${ }^{13} \mathrm{C}_{2}$-retinal (Fig. 1C) and determined the $\mathrm{H}-\mathrm{C}-\mathrm{C}-\mathrm{H}$ torsional angle around the $\mathrm{C} 14-\mathrm{C} 15$ bond in $\mathrm{PR}$ and $\mathrm{PR}_{\mathrm{E} 108 \mathrm{Q}}$ by double quantum spectroscopy. ${ }^{43}$ This angle reflects the orientation of the retinal polyene chain plane with respect to the Schiff base plane. In the ground state a signifcant out-of-plane twist of $158^{\circ} \pm 2^{\circ}$ is observed (Fig. 9A), which agrees with data previously reported by $\mathrm{us}^{32}$. For analyzing Kstate data, the $\mathrm{C} 14$ resonance (Fig. 5B) had to be deconvoluted into its ground and K-state contributions. The resulting $\mathrm{HCCH}$ evolution curve could be well described by a slightly altered torsion angle of $154^{\circ} \pm 3^{\circ}$ (Fig. 9B). For the M-state, $\mathrm{HCCH}$ evolution curves were obtained for C15_1 and C15_2 by separating the ground state contributions by spectral deconvolution (Fig. S8). Data analysis for C15_1 (163.7 ppm) reveals an angle of $148^{\circ} \pm 3^{\circ}$ (Fig. 9C) and for C15_2 (159.4 ppm) a value of $160^{\circ} \pm 4^{\circ}$ (Fig 9D). Torsion angle data are 
summarized in Table 1. The $\mathrm{HCCH}$ torsion angle in the ground state is identical in PR and $\mathrm{PR}_{\mathrm{E} 108 \mathrm{Q}}$ (Fig. S5), which offers an additional verification that this mutant is structurally very similar to the wild type. Furthermore deconvolution of residual ground state population in Kas well as in M-state spectra results in the ground state torsion angle, verifing the robustness of the experiment and the deconvolution procedure (Fig. S6).

\section{Discussion}

\section{K-state}

In the K-state, no ${ }^{15} \mathrm{~N}$ chemical shift change for the pSB nitrogen is observed (Fig. 5A). This is in contrast to data reported for other microbial rhodopsins: Upfield shifts of 8 ppm for $B^{25}$ and $15.5 \mathrm{ppm}$ for $\mathrm{ChR} 2^{31}$ have been reported. These shielding effects could be explained by an altered interaction between Schiff base and counter ion induced by the retinal isomerization: A wealth of structural data on BR cumulates in a picture in which the highlyordered keystone water molecule 402 connects SB, Asp85 and Asp212 in the ground state. Light-induced retinal isomerization disrupts the order of this water molecule in the K-state. ${ }^{44}$ Subsequently, the $\mathrm{H}$-bond between the SB and water 402 is destroyed, which would result in a ${ }^{15} \mathrm{~N}$ upfield shift. However, for PR, no corresponding water molecule has been detected so far, which could explain why the isomerization event does not affect the ${ }^{15} \mathrm{~N}$ Schiff base chemical shift.

In contrast to the Schiff base nitrogen, significant chemical shift changes are observed along the chain from $\mathrm{C} 10$ to $\mathrm{C} 14$ (Fig. 7A). The largest effects are observed for C11, C12 and C13 and, most remarkably, the chemical shift changes in an alternating fashion between shielding (C10, C12, C14) and de-shielding (C11, C13). In order to separate pure isomerization effects from additional protein-retinal interactions, known chemical shift changes from all-trans/13cis model compounds are overlaid with our experimental findings in Fig. 7A (black bars). This comparison reveals that the chemical shift changes of $\mathrm{C} 12$ and $\mathrm{C} 14$ are almost identical to those in model compounds. ${ }^{45-47}$ The large shielding of $\mathrm{C} 12$ is a result of the reduced distance between $\mathrm{C} 12$ and $\mathrm{C} 15$ in 13-cis compared to all-trans retinal ${ }^{45-47}$, which was also verified under our experimental conditions (Fig. S7). However, the values for C10, C11 and C13 deviate significantly. These changes and the alternating shielding/de-shielding pattern could be caused by an altered torsion of the polyene chain resulting in different chemical environment on both sides of the chain and/or modified protein-chromophore interactions in the K-state. The ground state crystal structure of the closely related blue $\mathrm{PR}^{14}$ shows that the retinal is sandwiched in the binding pocket between the two tryptophane residues Trp98 (helix C) and Trp197 (helix F). Furthermore, Tyr200 (helix F) is in close proximity. Carbons C11 and C13 are pointing towards Trp197 while C10, C12 and C14 are oriented towards Trp98 (Fig. S7). These residues are highly conserved and also found in BR. The consensus 
model for the latter involves light induced movements of helix $C$ towards $G$ and a retinal interaction with Trp182 (Trp197 in green PR) pushing helix F outward. ${ }^{44}$ Time-resolved WAXS data indicate at least similar conformational dynamics also in PR. ${ }^{48}$ One could therefore speculate that the de-shielding of $\mathrm{C} 11$ and $\mathrm{C} 13$ results from an increased distance and shielding of C10 by a closer proximity to Trp197 or Tyr200 in helix F (Fig. S7). Moreover, additional shielding effects arising from the delocalized pi-system in the retinal polyene chain and a rearrangement of bound water molecules might contribute to the observed chemical shift changes as well. Furthermore, the isomerization slightly increases the out-of-plane twist of the retinal as observed by the change of the $\mathrm{H}-\mathrm{C} 14-\mathrm{C} 15-\mathrm{H}$ dihedral angle (Figs. 9A, B). This reflects orientation changes between polyene chain and Schiff base and might be the first step towards the Schiff base orientation needed for the de-protonation step in the Mstate.

In summary, the retinal in the PR K-state shows large chemical shift changes in the middle of the polyene chain, which are different from pure isomerization effects while the Schiff base linkers remains unaffected, a situation different from $\mathrm{BR}^{25}$

\section{M-state}

We were able to trap the M-state by enhancing its low population by introducing the $\mathrm{E} 108 \mathrm{Q}$ mutation. Our control experiments show that this mutation does not cause any structural changes within the retinal binding pocket and therefore offers a valid approach for cryotrapping the M-state. It is noteworthy that the much higher populated M-state of BR allows a relatively straightforward trapping by choosing an appropriate illumination protocol without the need of additional mutations ${ }^{25,29,49}$. In contrast, a M-state in ChR2 could not be trapped. ${ }^{31}$ Interestingly, low populated M-states, i.e. deprotonated SB populations, are also observed in photocycles of other microbial proton pumps such as xanthorhodopsin $(X R)^{50}$ and rhodopsin from Gloeobacter violaceus $(\mathrm{GR})^{51}$. On the contrary, pumps found in eukaryotic organism like Leptoshaeria or Neurospora rhodopsin from fungi show higher M-state populations ${ }^{52,53}$. Any attempt to explain such differences would be highly speculative at this point but a correlation between the M-state population and proton pumping efficiency might be assumed. However, data to verify such a hypothesis are difficult to obtain. While BR can be considered as a 'robust' proton pump, the situation is less clear for PR under physiological conditions. PR most significantly enhances growth of the host cells under starving conditions, but does not increase growth of the cells in general ${ }^{54-56}$. It has also been suggested that PR is not optimized for a fast photocycle due to the formation of the His75-Asp97 cluster, which might be an indication for alternative/additional functions as a sensor or regulator. ${ }^{5,33,57}$ 
The successful trapping of the PR M-state was verified by the detection of a deprotonated Schiff base ${ }^{15} \mathrm{~N}$ resonance (Fig. $5 \mathrm{~A}$ ), which only appears in this part of the photocycle. The Kstate becomes completely de-populated (Fig. 5B) and resonances C11-15 change significantly from K- to M-state (Fig. 7). The observation of two $\mathrm{C} 13$ and $\mathrm{C} 15$ populations (Fig 6 ) and two signals for the deprotonated SB (Fig. 8) provide evidence for the existence of two sub-states $M_{1}$ (de-shielding of $C 15$ ) and $M_{2}$ (shielding of $C 15$ ), which agree well with optical data presented here (Fig. 4) and elsewhere ${ }^{58}$. The occurrence of two sub-states is also in accordance with similar data reported for $\mathrm{BR}^{59}$. They could be interpreted as a reflection of a two-stage reorientation of the deprotonated SB during the photocycle from the extracellular site directly after the de-protonation to the intracellular site just before reprotonation. This is supported by the two torsion angles measured for the M-state (Fig. 8): $\mathrm{M}_{1}$ could correspond to the extracellular $\left(148^{\circ}\right)$ and $M_{2}$ to the intracellular orientation $\left(160^{\circ}\right)$. In $M_{1}$, the $S B$ and the polyene chain plane seem highly twisted with respect to each other. Reorientation of the SB to the intracellular site for reprotonation $\left(\mathrm{M}_{2}\right)$ decreases the out-of-plane twist, resulting in a similar angle as in the ground state. A similar behavior has been observed for $\mathrm{BR}^{27}$.

The large chemical shift changes of C11, C12, C13 and C14 during the K- to M-state transition reflect the de-protonation of the Schiff base. To which extent the de-protonation event alone dominates the experimental data can be estimated from model compound studies by comparing ${ }^{13} \mathrm{C}$ chemical shifts of deprotonated all-trans $\mathrm{N}$-butyretinylideneimine Schiff base with all-trans N-butyretinylideneimine Schiff bases in complex with different counter ions (black bars in Fig. 7B). ${ }^{45}$ Our comparison reveals that the large shifts of +11.7 ppm for $\mathrm{C} 11,-3.9 \mathrm{ppm}$ for $\mathrm{C} 12$ and $+19.1 / 21.6 \mathrm{ppm}$ for $\mathrm{C} 13$ with respect to the K-state are fully within the range observed for these model compounds and can therefore be explained on the basis of electronic effects caused by the Schiff base de-protonation alone. Therefore, additional protein-retinal interactions can be excluded for this middle part of the polyene chain. On the contrary, the observed changes for C14 and C15 clearly deviate from those in model compounds. One reason could be found in counter ion differences, since e.g. chloride and bromide are used in the model compounds in contrast to the carboxyl groups of the residues forming the counter ion complex in PR. For C14 and C15_1, de-shielding has been observed compared to the K-state, which is most likely caused by weaker interaction with the counter ion complex due to protonation of Asp97. An additional factor could be an increased distance to Asp227, as it has been reported for $B R .^{26}$ These factors could be less pronounced in $\mathrm{M}_{2}$ due to the reduced chain twist resulting in a small additional shielding of C15_2.

Our data for the transition from ground to K-state clearly illustrate that the changes in the retinal conformation as sampled by ${ }^{13} \mathrm{C}$ chemical shifts and dihedral angles not only depends 
on the all-trans/13-cis isomerization, but is strongly coupled to the protein environment. In contrast, the observed changes associated with the $\mathrm{K}$ to $\mathrm{M}$ transition are primarily controlled by the de-protonation reaction alone. Interestingly, the comparison of our experimental results with data from model compounds also suggests, that the chemical shift changes induced by isomerization or de-protonation are additive. To elucidate the structural basis of the observed chemical shift changes in more detail, further studies such as quantum chemical calculations will be needed.

\section{Conclusions}

Here, we have presented the first structural data of the retinal chromophore in proteorhodopsin in the $\mathrm{K}$ - and M-state based on DNP-enhanced solid-state NMR spectroscopy. Our observations show that chemical shift changes are strongest in the middle of the retinal polyene chain and less pronounced towards the Schiff base linkage, which demonstrate a distorted retinal structure and significant protein-chromophore interactions during the ground- to K-state transition. In the K-state, an alternating shielding/de-shielding pattern propagating away from the Schiff base is observed indicating that especially the middle part of the chain responses to the isomerization and experiences an altered interaction within the retinal binding pocket. The M-state shows very large chemical shift differences and splits into two populations reflecting the reorientation of the Schiff base between de- and reprotonation events, which explains the results of time-resolved optical spectroscopy. With the here introduced illumination and trapping protocol in combination with DNP-enhanced solid-state NMR, it will be possible to fully resolve the retinal binding pocket during the photocycle of PR and other microbial rhodopsins. Such data are required to resolve how apparently similar architectures can encode such a diversity of functions ranging from ion pumping, to gating and sensing.

\section{Material and Methods}

${ }^{13} \mathrm{C}$-labeled retinal: $14,15-{ }^{13} \mathrm{C}_{2}$-E-retinal $\left({ }^{13} \mathrm{C}_{2}\right.$-retinal); $10,11,12,13,14,15-{ }^{13} \mathrm{C}_{6}$-E-retinal $\left({ }^{13} \mathrm{C}_{6}\right.$ retinal); and $12,15^{13} \mathrm{C}_{2}$-E-retinal were synthesized as described elsewhere. ${ }^{60}$ The ${ }^{13} \mathrm{C}_{6}$-retinal was also contained ${ }^{13} \mathrm{C}$-methyl groups at positions $\mathrm{C} 16, \mathrm{C} 17$ and $\mathrm{C} 18$. Due to their relaxation properties, these resonances could not be observed under DNP conditions and they were therefore omitted.

Protein expression, purification and reconstitution:

$\mathrm{PR}$ (eBAC31A08) as well as $\mathrm{PR}_{\mathrm{E} 108 \mathrm{Q}}$ was expressed in C43 E. coli cells in a defined medium containing all amino acids: $0.5 \mathrm{~g} / \mathrm{l}$ alanin, $0.4 \mathrm{~g} / \mathrm{l}$ arginine, $0.4 \mathrm{~g} / \mathrm{l}$ aspartate, $0.05 \mathrm{~g} / \mathrm{l}$ cysteine, $0.4 \mathrm{~g} / \mathrm{l}$ glutamine, $0.65 \mathrm{~g} / \mathrm{l}$ glutamate, $0.55 \mathrm{~g} / \mathrm{l}$ glycine, $0.1 \mathrm{~g} / \mathrm{l}$ histidine, $0.23 \mathrm{~g} / \mathrm{l}$ isoleucine, 
$0.23 \mathrm{~g} / \mathrm{l}$ leucine, $0.2 \mathrm{~g} / \mathrm{l}^{15} \mathrm{~N}$-lysine, $0.25 \mathrm{~g} / \mathrm{l}$ methionine, $0.13 \mathrm{~g} / \mathrm{l}$ phenylalanine, $0.1 \mathrm{~g} / \mathrm{l}$ proline, $2.1 \mathrm{~g} / \mathrm{l}$ serine, $0.23 \mathrm{~g} / \mathrm{l}$ threonine, $0.17 \mathrm{~g} / \mathrm{l}$ tyrosine, $0.23 \mathrm{~g} / \mathrm{l}$ valine, $0.5 \mathrm{~g} / \mathrm{l}$ adenine, $0.65 \mathrm{~g} / \mathrm{l}$ guanosine, $0.2 \mathrm{~g} / \mathrm{l}$ thymine, $0.5 \mathrm{~g} / \mathrm{l}$ uracil, $0.2 \mathrm{~g} / \mathrm{l}$ cytosine, $1.5 \mathrm{~g} / \mathrm{l}$ sodium acetate, $1.5 \mathrm{~g} / \mathrm{l}$ succinic acid, $0.5 \mathrm{~g} / \mathrm{l} \mathrm{NH}{ }_{4} \mathrm{Cl}, 0.85 \mathrm{~g} / \mathrm{l} \mathrm{NaOH}, 10.5 \mathrm{~g} / \mathrm{l} \mathrm{K}{ }_{2} \mathrm{HPO}_{4}, 20 \mathrm{~g} / \mathrm{l}$ glucose, 4 mM MgSO 4 , $0.05 \mathrm{mM} \mathrm{FeCl}_{3}, 10 \mathrm{ml} / \mathrm{l}$ trace metal solution $\left(20 \mathrm{mg} \mathrm{CaCl}_{2}, 20 \mathrm{mg} \mathrm{ZnSO}\right.$, 20 mg $\mathrm{MnSO}_{4}, 500$ $\mathrm{mg}$ tryptophane, $500 \mathrm{mg}$ thiamine, $500 \mathrm{mg}$ niacin, $10 \mathrm{mg}$ biotin), $0.1 \mathrm{mg} / \mathrm{l}$ kanamycin. In this way, specifically lysine labeled protein could be produced. Cells were grown in $0.5 \mathrm{l}$ cultures at $37^{\circ} \mathrm{C}$ until $\mathrm{OD}_{600}=0.6-0.8$ was reached. Protein expression was induced by $1 \mathrm{mM}$ IPTG. Cells were grown at $37^{\circ} \mathrm{C}$ for another $3.5 \mathrm{~h}$ and subsequently harvested. Cell disruption and membrane preparation took places as described before. ${ }^{33}{ }^{13} \mathrm{C}_{2^{-}}$or ${ }^{13} \mathrm{C}_{6}$-retinal was added during solubilization in $1.5 \% \mathrm{n}$-Dodecyl $\beta$-D-maltoside (DDM) at $4^{\circ} \mathrm{C}$ overnight. Protein was purified by Ni-NTA and reconstituted in a 1,2-dimyristoyl-sn-glycero-3-phosphocholine (DMPC): 1,2-dimyristoyl-sn-glycero-3-phosphate (DMPA) $(9: 1$ (w/w)) mixture in a lipid-toprotein ratio (LPR) of $2(\mathrm{w} / \mathrm{w})$ as described before. ${ }^{33}$ The proteoliposomes were washed several times with buffer (50mM Tris, $5 \mathrm{mM} \mathrm{MgCl}_{2}, \mathrm{pH}$ 9) to adjust the $\mathrm{pH}$ and pelleted in by ultracentrifugation afterwards. In order to achieve signal enhancement with DNP, the samples were incubated with $20 \mathrm{mM} \mathrm{AMUPOL}^{40}\left(60 \% \mathrm{D}_{2} \mathrm{O}, 30 \% \mathrm{~d}_{8}\right.$-glycerol, $\left.10 \% \mathrm{H}_{2} \mathrm{O}\right)$ for $14 \mathrm{~h}$ at $4^{\circ} \mathrm{C}$. The excess polarizing agent was removed next day. About $1.5 \mathrm{mg}$ of protein was packed in a $3.2 \mathrm{~mm}$ sapphire rotor and spun in a rotor testing device for a few minutes at room temperature in order to spread the sample equally one the inner surface of the MAS rotor.

Illumination and intermediate trapping: For illumination high-power LEDs from Mightex were used. The K-state was trapped by direct illumination of PR samples within the DNP probe at $100 \mathrm{~K}$ for $40 \mathrm{~min}$. The light was transferred into the probe via a glass fiber. After illumination, the sample was directly measured without further illumination. Sample transparency was found to decrease slightly at lower temperature. Therefore, the use of slightly blue-shifted LED at higher power (470 nm, 3.3 W), which maximizes light scattering through the sample, was found to yield a higher trapping efficiency compared to a $525 \mathrm{~nm}$ LED $(0.13 \mathrm{~W})$ (for further details see Fig. S9). The M-state was trapped by illuminating $P R_{E 108 Q}$ samples outside of the DNP probe for $1.5 \mathrm{~min}$ using a $525 \mathrm{~nm}$ LED $(0.13 \mathrm{~W})$ at room temperature. Subsequently, samples were flash-frozen in liquid nitrogen within the pre-cooled rotor catcher and transferred into the DNP probe pre-cooled at $100 \mathrm{~K}$.

DNP-enhanced solid-state NMR experiments: All experiments were performed on a Bruker 400 DNP system consisting of a $400 \mathrm{MHz}$ WB Advance II NMR spectrometer, a $263 \mathrm{GHz}$ Gyrotron as microwave source and a $3.2 \mathrm{~mm} \mathrm{HCN}$ Cryo-MAS probe. For $1 \mathrm{D}$ and $2 \mathrm{D}{ }^{13} \mathrm{C}$ spectra a MAS frequency of $8 \mathrm{kHz}$ and for $1 \mathrm{D}{ }^{15} \mathrm{~N}$ spectra $10 \mathrm{kHz}$ was used. During DNP 
experiments the temperature was kept at around $100 \mathrm{~K} \cdot{ }^{13} \mathrm{C}$ and ${ }^{15} \mathrm{~N}$ referencing was done indirectly to DSS using ${ }^{13} \mathrm{C}$ signal of adamantane at $40.49 \mathrm{ppm}$ at room temperature. For all experiments $100 \mathrm{kHz}$ decoupling using SPINAL-64 ${ }^{61}$ was applied during acquisition. The initial ${ }^{13} \mathrm{C}$ CP step for the proton driven spin diffusion experiment ${ }^{42}$ (PDSD) was achieved using a contact time of $0.8 \mathrm{~ms}$. A mixing time of $20 \mathrm{~ms}$ was used and a recycle delay of $3 \mathrm{~s}$ was applied. In the indirect dimension, an acquisition time of $4.8 \mathrm{~ms}, 292$ increments, and 192 scans per increment were used. ${ }^{13} \mathrm{C}$-double quantum filter experiments (DQFexperiments) were obtained using the POST-C $7^{62}$ sequence for double quantum excitation and reconversion at $0.5 \mathrm{~ms}$. 2D Double quantum single quantum (DQSQ) spectra ${ }^{41}$ were recorded with 254 increments in the indirect dimension with 384 scans and $17.86 \mu$ s dwell time. For ${ }^{15} \mathrm{~N}-{ }^{13} \mathrm{C}$ correlation, a TEDOR sequence with $\mathrm{z}$-filter and a mixing time $\mathrm{T}_{\text {mix }}=6.8 \mathrm{~ms}$ was applied. ${ }^{63}$ The ${ }^{15} \mathrm{~N}$ offset was set between the signal of the protonated and the deprotonated Schiff base at $10000 \mathrm{~Hz}$. Spectra were recorded with 2048 scans in direct and 64 increments with $100 \mu s$ each in indirect dimension.

Dihedral angle determination:

For $\mathrm{HCCH}$ torsional angle measurements a double quantum heteronuclear local field experiment ${ }^{64}$ was applied ( $\mathrm{HCCH}$-experiment). In the experiment POST-C7 during two rotor periods was used for double quantum excitation and reconversion, PMLG-9 ${ }^{65}$ at $106.2 \mathrm{kHz}$ was used for homonuclear ${ }^{1} \mathrm{H}$ decoupling and ${ }^{1} \mathrm{H} \mathrm{CW}$ irradiation at $106.2 \mathrm{kHz}$ was used during the constant time periods. Each data point was recorded with 4096 scans. The peaks corresponding to the different photointermediates were deconvoluted with TOPSPIN 2.1 (see Fig. S6). The measured peak intensities are fitted with torsion angle data, which have been simulated with SIMPSON ${ }^{66}$ as it has been described before. ${ }^{31}$

Time-resolved absorption spectroscopy: The flash photolysis experiments have been performed with an OPO (optical parametric oscillator) combined with an Nd:YAG laser (Spitlight 600 , Innolas Laser $\mathrm{GmbH}$ ) for the generation of nanosecond pump pulses. The probe pulses were generated by a Xenon flash lamp delivering microsecond white light pulses. For detection, an intensified charge-coupled device camera (ICCD camera) was deployed (PI-MAX 3, Princeton Instruments). The transient data are analyzed with a global lifetime analysis (GLA) method, conducted with the program "OPTIMUS" ${ }^{67}$. In this routine, data are analyzed based on a fixed set of exponential terms resulting in decay-associated spectra for each lifetime ${ }^{68}$.

Acknowledgement: The work was funded by the Cluster of Excellence Macromolecular Complexes Frankfurt (DFG EXC 115) and DFG/SFB 807 'Transport and communication across membranes' and. The DNP experiments were enabled through an equipment grant to 
CG provided by DFG (GL 307/4-1). AJL, LJB and RCDB acknowledge the EPSRC for funding (EP/K039466/1, and EP/L505067/1).

Supporting Information: Thermal relaxation data (Fig. S1); Transient absorption of $\mathrm{PR}_{\mathrm{E} 108 \mathrm{Q}}$ (Fig. S2); Supporting PDSD and DQSQ spectra of $\mathrm{PR}_{\mathrm{E} 108 \mathrm{Q}}$ (Fig. S3); NMR data of the trapped K-state of $\mathrm{PR}_{\mathrm{E} 108 \mathrm{Q}}$ (Fig. S4); $\mathrm{HCCH}$ double quantum evolution curve for ${ }^{13} \mathrm{C}_{2}$-retinal in $\mathrm{PR}_{\mathrm{E} 108 \mathrm{Q}}$ (Fig. S5); Spectral deconvolution for $\mathrm{HCCH}$ analysis (Fig. S6); Supporting data for 12,15- ${ }^{13} \mathrm{C}_{2}$-E-retinal (Fig. S7); Supporting illustration for retinal-opsin interactions in PR (Fig. S8); Optimized illumination for K-state trapping (Fig. S9). This material is available free of charge via the Internet at http://pubs.acs.org. 
Figures and Legends
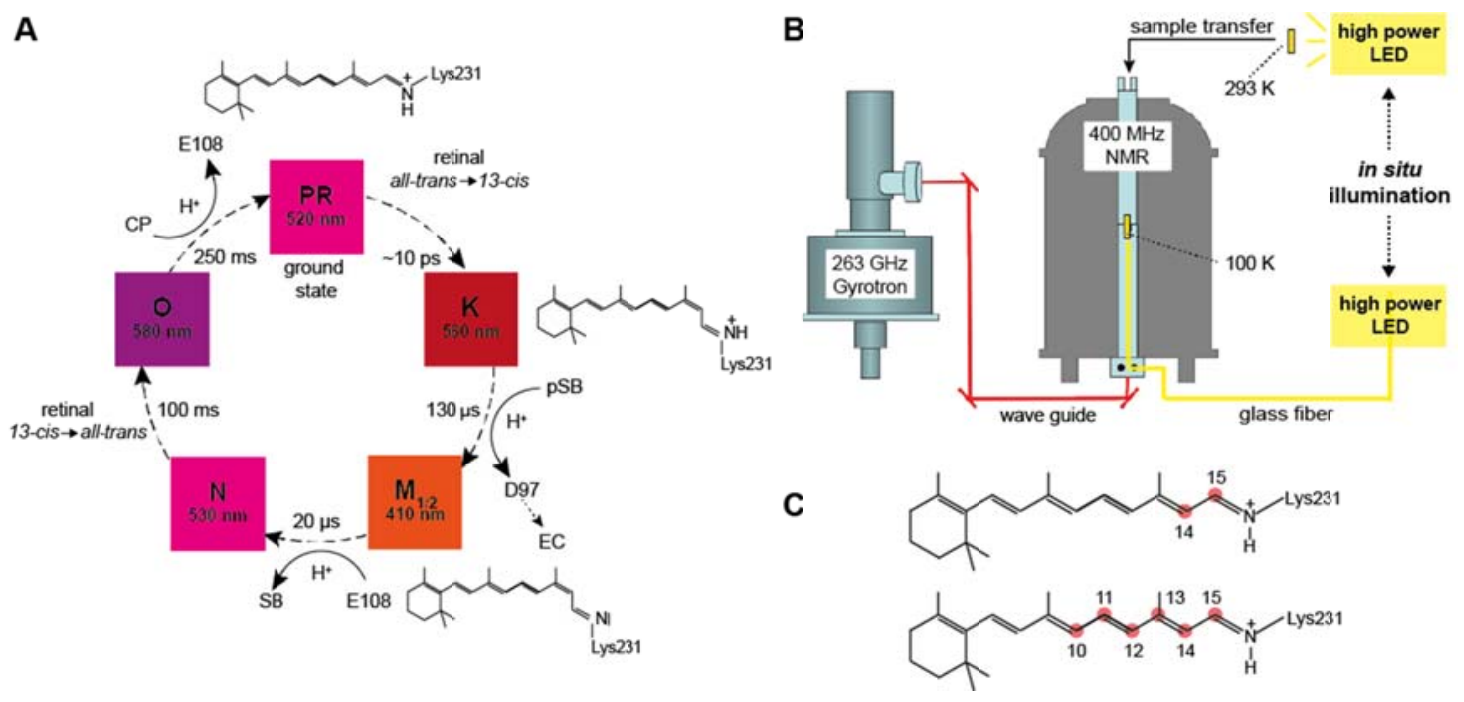

Figure 1: $(A)$ The PR photocycle is initiated by the light-induced isomerization of retinal from all-trans,15-anti to 13-cis,15-anti leading to the K-state. Next, the Schiff base transfers its proton to the primary proton acceptor Asp97 resulting in the blue shifted M-state. Subsequently, the Schiff base is reprotonated from the proton donor Glu108 leading to the formation of the $\mathrm{N}$-intermediate. In the last two steps the retinal reisomerization takes place (O-state) followed by proton uptake from the cytoplasma and reprotonation of E108. ${ }^{10}$ (B) Two in situ illumination schemes used here for DNP enhanced NMR measurements. Samples can be illuminated directly within the MAS probe under cryogenic conditions or at room temperature followed by rapid freezing and subsequent sample transfer into the magnet. (C) Retinal labeling schemes $14,15-{ }^{13} \mathrm{C}_{2}-E$-retinal $\left({ }^{3} \mathrm{C}_{2}\right.$-retinal $)$ and $10,11,12,13,14,15-{ }^{13} \mathrm{C}_{6}$-E-retinal $\left({ }^{13} \mathrm{C}_{6}\right.$-retinal). 
1

2

3

4

5

6

7

8

9

10

11

12

13

14

15

16

17

18

19

20

21

22

23

24

25

26

27

28

29

30

31

32

33

34

35

36

37

38

39

40

41

42

43

44

45

46

47

48

49

50

51

52

53

54

55

56

57

58

59

60

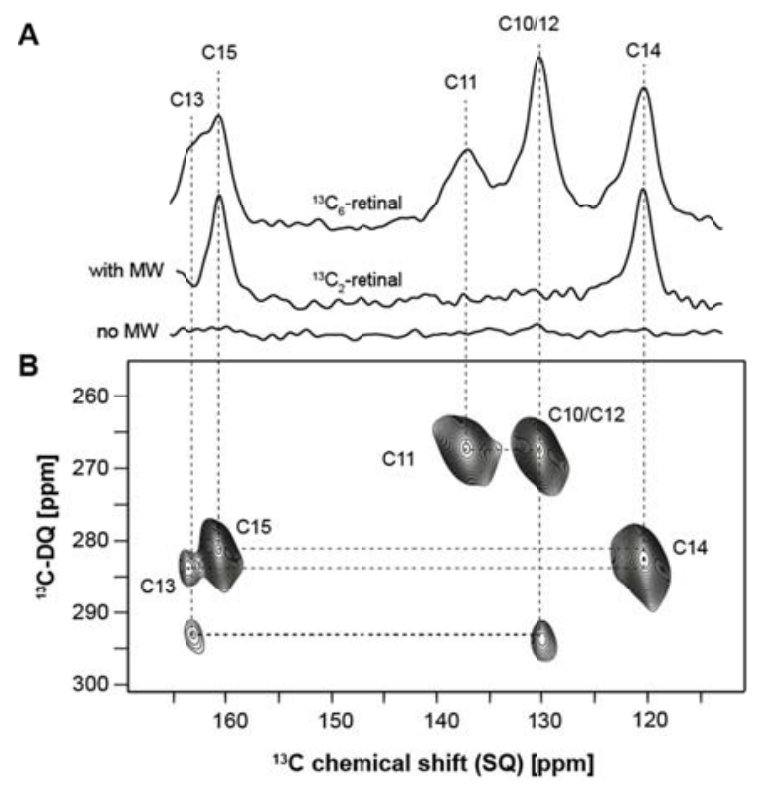

Figure 2: (A) DNP-enhanced, double-quantum filtered (DQF) ${ }^{13} \mathrm{C}$ spectra of $P R$ with ${ }^{13} \mathrm{C}_{2}$ and ${ }^{13} \mathrm{C}_{6}$ retinal. DNP enhancement is approx. 50-fold. (B) DNP-enhanced DQ-SQ spectrum of ${ }^{13} \mathrm{C}_{6}$-retinal in the PR ground state. The assigned chemical shifts are summarized in Table 1. 


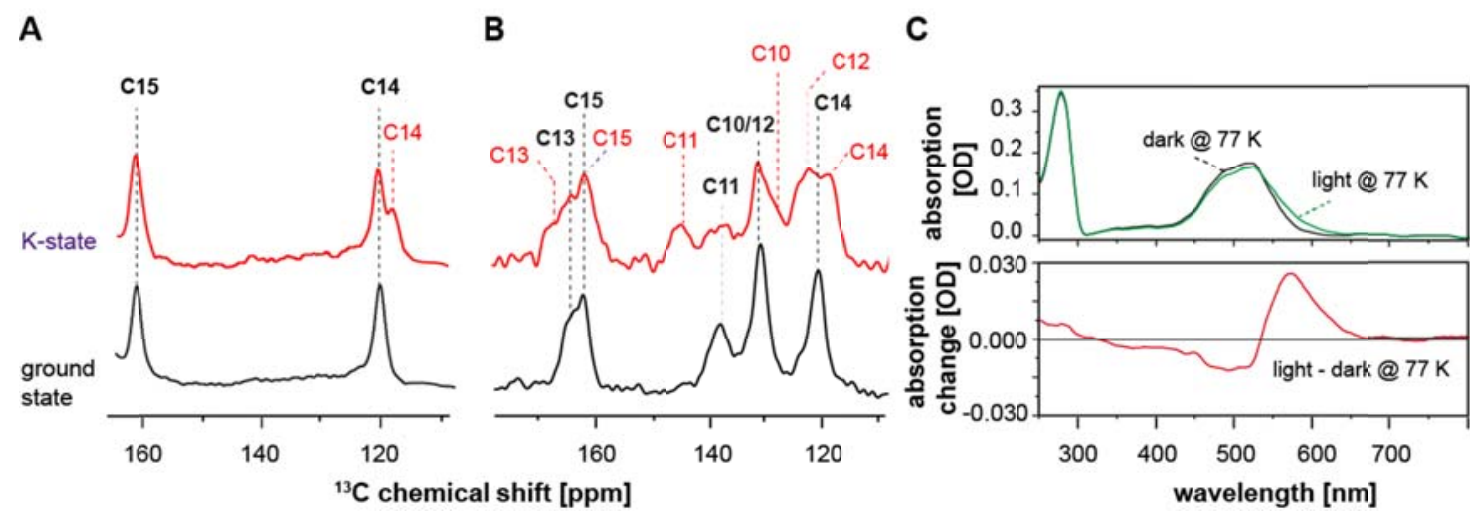

Figure 3: (A) DNP-enhanced ${ }^{13} \mathrm{C}$-DQF spectra of ${ }^{13} \mathrm{C}_{2}$-retinal and $(\mathrm{B}){ }^{13} \mathrm{C}_{6}$-retinal in the PR ground state (black, bottom) and upon $40 \mathrm{~min}$ in situ illumination of the sample in the DNPMAS probe at $\sim 100 \mathrm{~K}$ (top). The new set of signals is assigned to the K-state. (C) Optical absorption (top) and difference spectra (bottom) of dark- and light-illuminated PR at $77 \mathrm{~K}$ under conditions close to the DNP experiment. The difference spectrum reveals the occurrence of the K-state. 
A

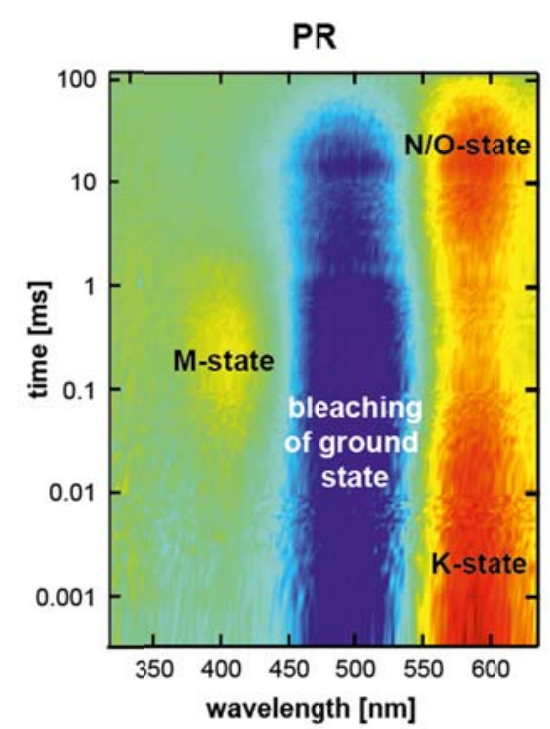

C

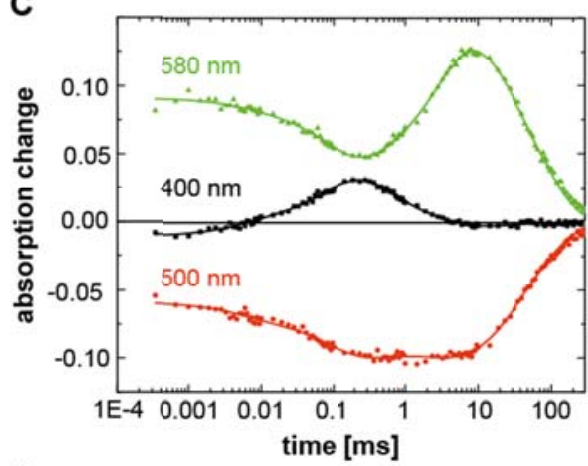

E

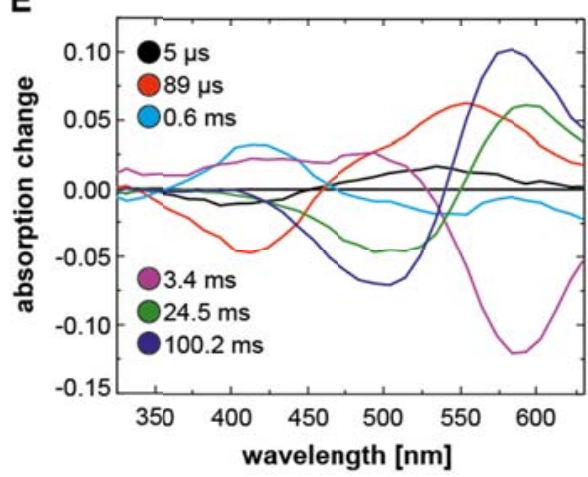

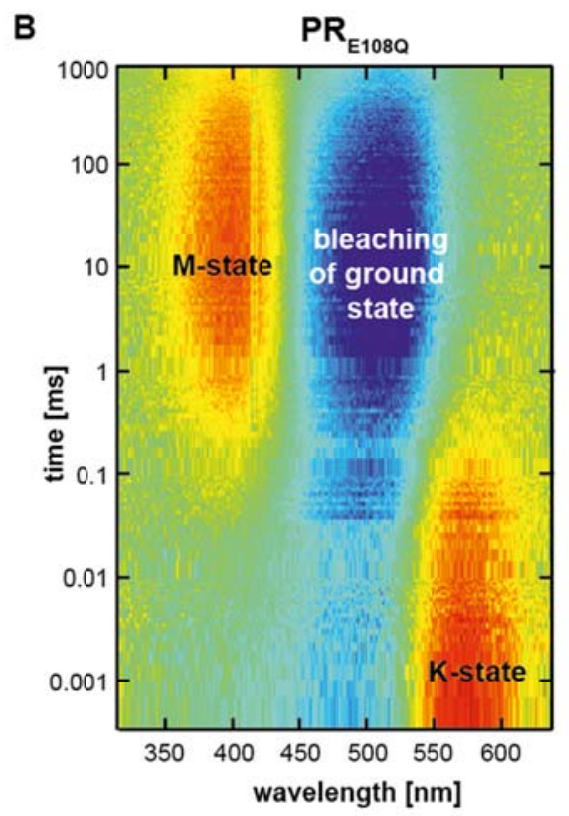

D

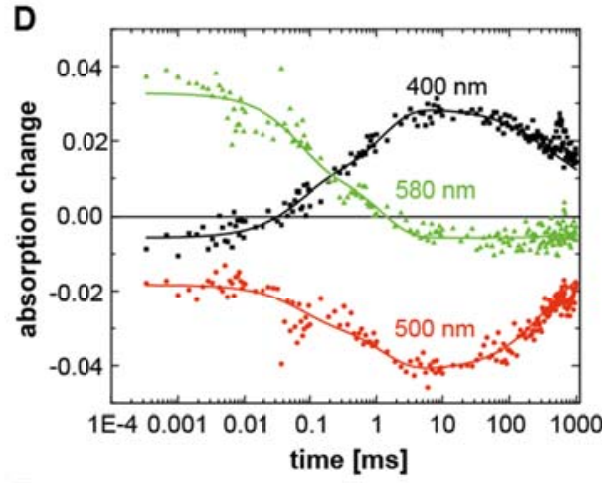

$\mathbf{F}$

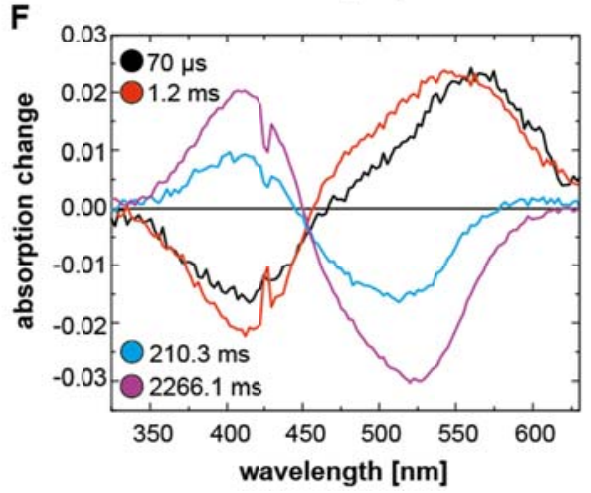

Figure 4: Photocycle of wild type $P R$ in comparison to the $P R_{E 108 Q}$ mutant. 2D plots of transient absorption in the UV-Vis spectral region of $P R(A)$ and $P R_{E 108 Q}(B)$. Red depicts positive, blue negative and green no absorption change. Transient absorption at $400 \mathrm{~nm}, 500$ $\mathrm{nm}$ and $580 \mathrm{~nm}$ of PR (C) and PR $\mathrm{E}_{\mathrm{E} 108 \mathrm{Q}}$ (D). The solid lines depict the fits of the data (dots). Decay associated spectra resulting from the global lifetime analysis for $P R(E)$ and $P R_{E 108 Q}$ $(\mathrm{F})$. 
A

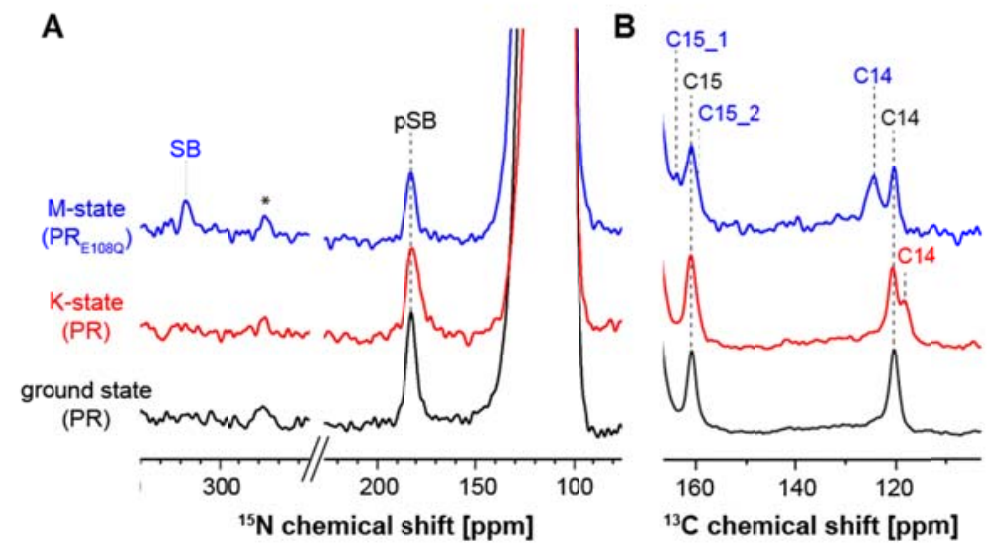

Figure 5: (A) DNP-enhanced ${ }^{15} \mathrm{~N}$ spectra of $\mathrm{PR}$ and $\mathrm{PR}_{\mathrm{E} 108 \mathrm{Q}}$ in ground, $\mathrm{K}$ - and M-states. In the K-state, the chemical shift of the pSB at $181 \mathrm{ppm}$ does not change compared to the ground state. In the M-state a deprotonated SB population at around $316 \mathrm{ppm}$ is detected, which verifies the accumulation of the $M$-intermediate (* denotes a spinning side band). (B) Comparison of DNP-enhanced ${ }^{13} \mathrm{C}$ spectra of ${ }^{13} \mathrm{C}_{2}$-retinal in PR in the ground- and $\mathrm{K}$-states with ${ }^{13} \mathrm{C}_{2}$-retinal in $\mathrm{PR}_{\mathrm{E} 108 \mathrm{Q}}$ in the M-state. An additional set of resonances for $\mathrm{C} 14$ and $\mathrm{C} 15$ occurs. The K-state becomes completely de-populated as seen for the $\mathrm{C} 14$ signals (the resonance above $162 \mathrm{ppm}$ is from additional isotope labeling within the protein). 

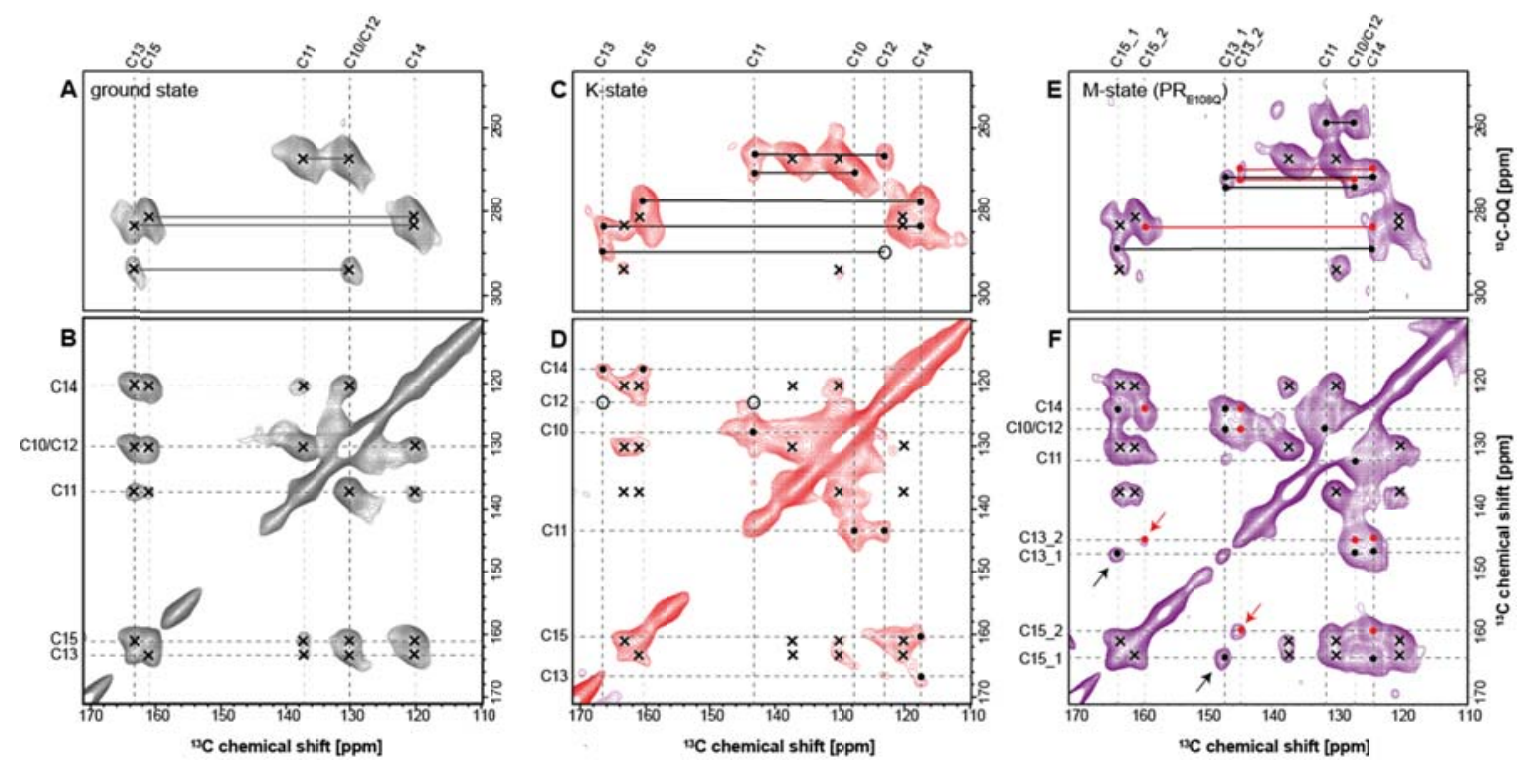

Figure 6: DNP-enhanced DQSQ $(A, C, E)$ and PDSD (B, D, F) spectra of ${ }^{13} \mathrm{C}_{6}$-retinal within $P R$ in the ground state $(A, B)$, in the K-state $(C, D)$ and in the $M$-state $(E, F)$. The M-state was created by thermal trapping of $\mathrm{PR}_{\mathrm{E} 108 \mathrm{Q}}$. For ground state $\mathrm{PR}$, single bond double-quantum correlations $\left(\omega_{1}+\omega_{2}\right)$ and cross peaks are highlighted by ( $\left.\mathrm{\square}\right)$ in $(A)$ and $(B)$. In the K-state, single bond double-quantum correlations $\left(\omega_{1}+\omega_{2}\right)$ and cross peaks are labeled with $(\cdot)$ in (C) and (D). Positions where residual ground state signal intensities are expected are indicated with (ם). Correlations, which could not be detected due to low signal intensities are labeled with (0). The M-state spectrum contains residual ground state signals (a) and two sets of single bond double-quantum correlations $\left(\omega_{1}+\omega_{2}\right)$ and cross peaks marked with $(\cdot)$ and $(\cdot)$. Arrows in $(F)$ indicate two-bond correlations between C13_1/C15_1 and C13_2/C15_2 in order to label both M-state spin systems unambiguously. Chemical shifts are summarized in Table 1. 


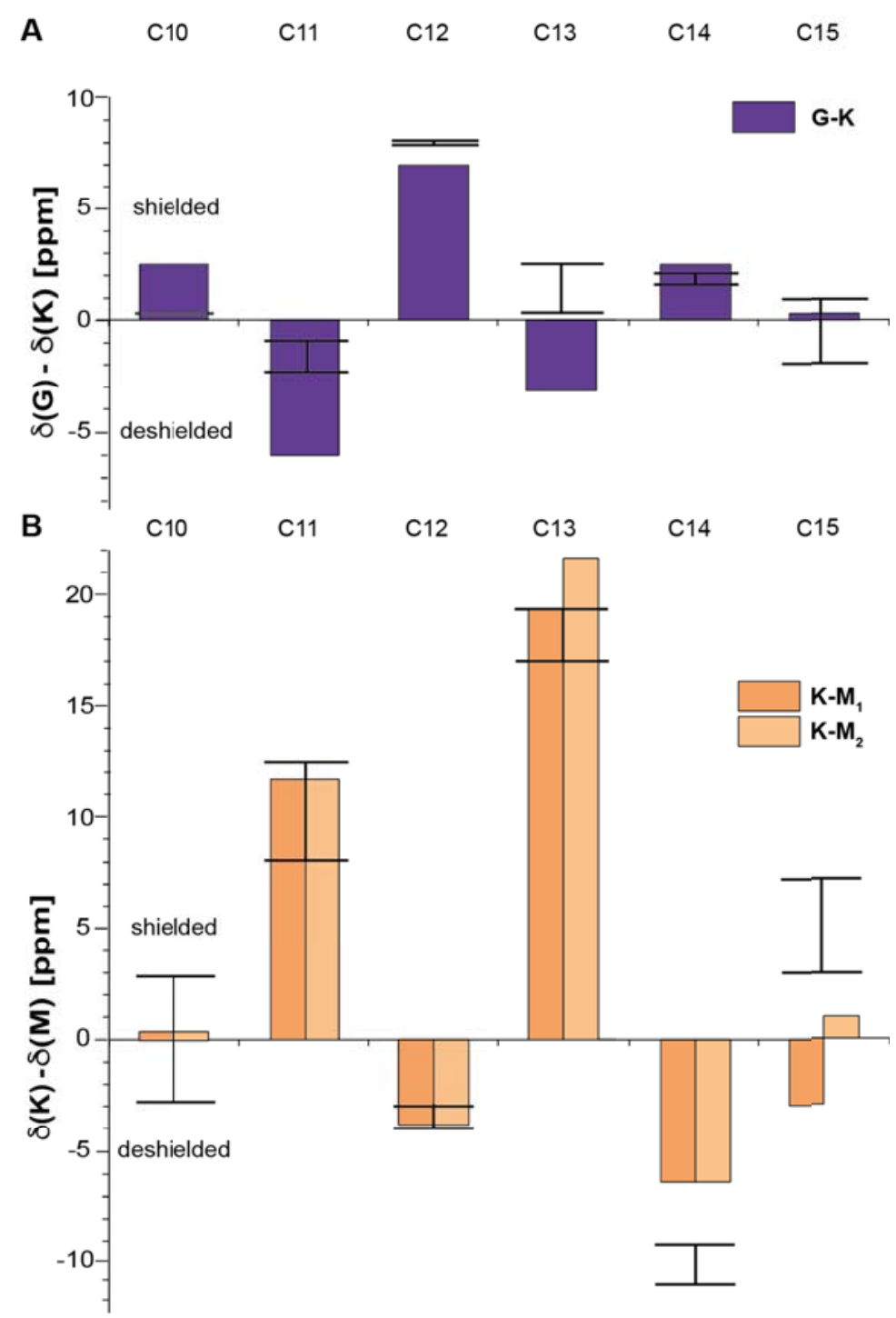

Figure 7: Light-induced chemical shift changes observed for retinal carbon atoms $\mathrm{C} 10-\mathrm{C} 15$ in PR plotted as the difference between ground- and K-state $(A)$ and between $K-$ and $M_{1} / M_{2}-$ states (B). The black bars illustrate the effect of the all-trans-13-cis isomerization as reported for retinal model compounds ${ }^{45-47}(A)$ and the effect of de-protonation of Schiff base analogs (N-butyretinyllideneimine $\left.{ }^{45},(\mathrm{~B})\right)$. 
Figure 8: DNP-enhanced ${ }^{15} \mathrm{~N}-{ }^{13} \mathrm{C}$ TEDOR spectrum of ${ }^{13} \mathrm{C}_{6}$-retinal in ${ }^{15} \mathrm{~N}-L y s-P_{E 108 Q}$ in the M-state $\left(t_{\text {mix }}=6.8 \mathrm{~ms}\right)$. Here, magnetization is transferred via TEDOR from the ${ }^{15} \mathrm{~N}$ of the $\mathrm{pSB} / \mathrm{SB}$ to the retinal chain. Cross-peaks with $\mathrm{C} 15$ and $\mathrm{C} 14$ are detected in ground and Mstate populations. In the M-state, two different correlations between the SB nitrogen and C15_1 and C15_2 are observed. A correlation with C13 is only detected in the ground state. 


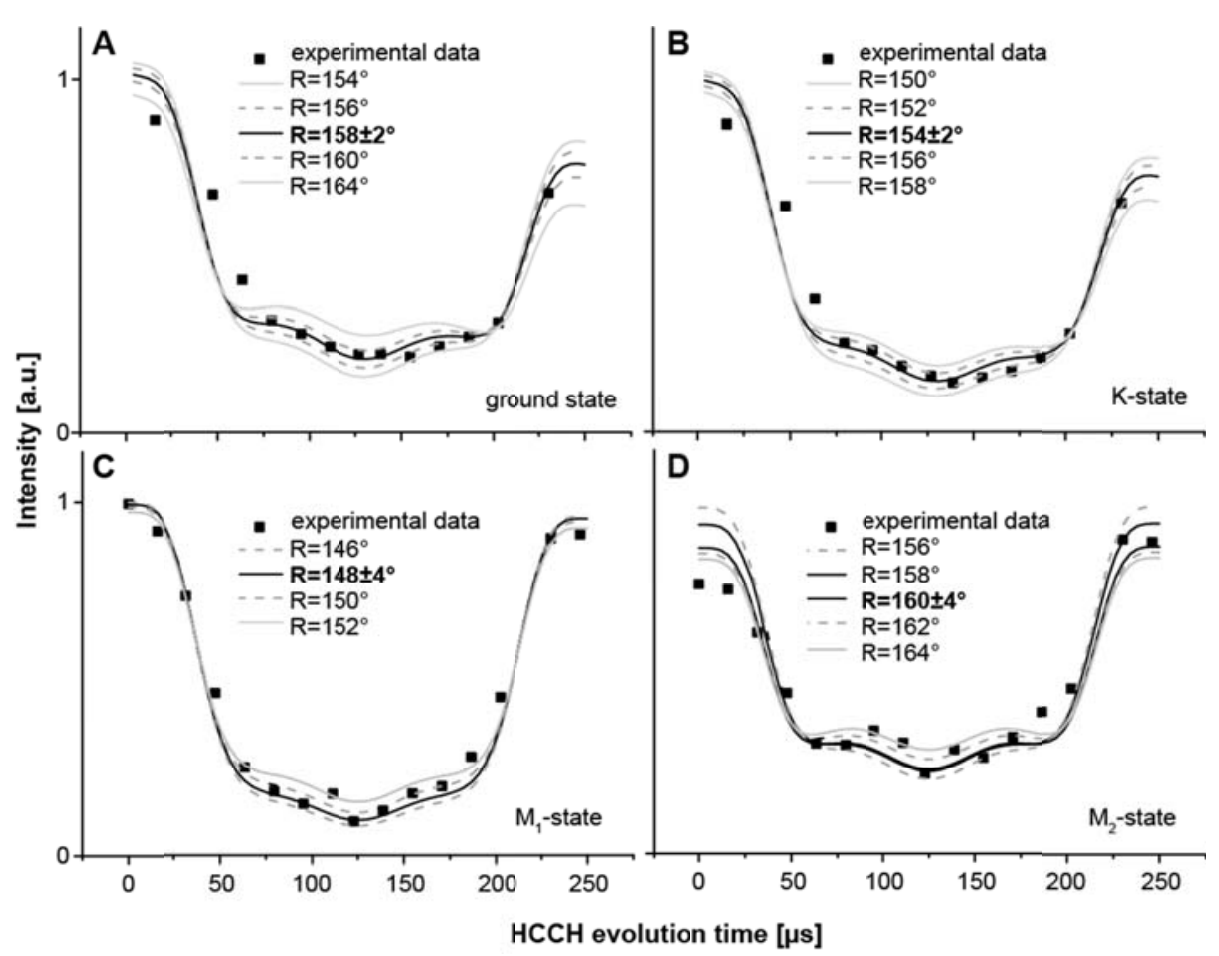

Figure 9: $\mathrm{HCCH}$ dephasing curves for the $\mathrm{C} 14-\mathrm{C} 15$ spin system in $\mathrm{PR}$ recorded over two rotor periods reporting on the $\mathrm{HCCH}$ dihedral angle: $(\mathrm{A})$ ground state $\left(158^{\circ} \pm 2^{\circ}\right)$; (B) K-state $\left(154^{\circ} \pm 2^{\circ}\right)$, the dephasing curve was obtained by de-convolution of the $\mathrm{C} 14$ resonance (Fig. $5 B)$; (C) $\mathrm{M}_{1}$-state $\left(148^{\circ} \pm 4^{\circ}\right)$ and (D) $\mathrm{M}_{2}$-state $\left(160^{\circ} \pm 4^{\circ}\right)$. The $\mathrm{C} 15$ resonance was deconvoluted into both M-state contributions $\left(\mathrm{C} 15_{1}, \mathrm{C} 15_{2}\right)$ and separated from the remaining ground state population (see Fig. S6 for deconvolution details). 
1

2

3

4

5

6

7

8

9

Table 1: Chemical shifts and torsion angles $(\mathrm{H}-\mathrm{C} 14-\mathrm{C} 15-\mathrm{H})$ for $\mathrm{PR}$ in ground and $\mathrm{K}$-state and $\mathrm{PR}_{\mathrm{E} 108 \mathrm{Q}}$ in M-state.

\begin{tabular}{|c|c|c|c|c|c|c|c|}
\hline Atom & $\begin{array}{c}\text { ground state } \\
{[\mathrm{ppm}]}\end{array}$ & $\begin{array}{c}\text { K-state } \\
\text { [ppm] }\end{array}$ & $\begin{array}{c}\mathrm{M}_{1} \text {-state } \\
\text { [ppm] }\end{array}$ & $\begin{array}{c}\mathrm{M}_{2} \text {-state } \\
{[\mathrm{ppm}]}\end{array}$ & $\begin{array}{l}\text { G-K } \\
{[\mathrm{ppm}]}\end{array}$ & $\begin{array}{c}\text { G-M } \mathrm{M}_{1} / \mathrm{M}_{2}{ }^{(2)} \\
{[\mathrm{ppm}]}\end{array}$ & $\begin{array}{r}\mathrm{K}-\mathrm{M}_{1} / \mathrm{M}_{2}{ }^{(3)} \\
{[\mathrm{ppm}]}\end{array}$ \\
\hline C10 & $130.0 \pm 0.5$ & $127.6 \pm 0.5$ & $127.0 \pm 0.5$ & - & 2.4 & 3.0 & 0.6 \\
\hline C11 & $137.3 \pm 0.5$ & $143.3 \pm 0.5$ & $131.6 \pm 0.5$ & - & -6.0 & 5.7 & 11.7 \\
\hline C12 & $130.0 \pm 0.5$ & $123.1 \pm 0.5$ & $127.0 \pm 0.5$ & - & 6.9 & 3.0 & -3.9 \\
\hline C13 & $163.2 \pm 0.5$ & $166.3 \pm 0.5$ & $147.2 \pm 0.5$ & $144.7 \pm 0.5$ & -3.1 & $16.0 / 18.5$ & $19.1 / 21.6$ \\
\hline C14 & $120.2 \pm 0.5$ & $117.7 \pm 0.5$ & $124.1 \pm 0.5$ & - & 2.5 & -3.9 & -6.4 \\
\hline C15 & $160.8 \pm 0.5$ & $160.6 \pm 0.5$ & $163.7 \pm 0.5$ & $159.4 \pm 0.5$ & 0.2 & $-2.9 / 1.4$ & $-3.1 / 1.2$ \\
\hline${ }^{15} \mathrm{~N}$ SB & $181 \pm 1$ & $181 \pm 1$ & $316 \pm 1$ & $312 \pm 1$ & 0 & $-135 /-131$ & $-135 /-131$ \\
\hline $\begin{array}{l}\text { H-C14-C15-H } \\
\text { dihedral angle }\end{array}$ & $158^{\circ} \pm 2$ & $154^{\circ} \pm 3$ & $148^{\circ} \pm 3$ & $160^{\circ} \pm 4$ & $4^{\circ}$ & $10^{\circ} /-2^{\circ}$ & $6^{\circ} / 6^{\circ}$ \\
\hline
\end{tabular}

(1) Chemical shift difference between ground- and K-state

(2) Chemical shift difference between ground- and $M_{1} / M_{2}$-states

(3) Chemical shift difference between $\mathrm{K}$ - and $\mathrm{M}_{1} / \mathrm{M}_{2}$-states 


\section{References}

(1) Beja, O.; Aravind, L.; Koonin, E. V.; Suzuki, M. T.; Hadd, A.; Nguyen, L. P.; Jovanovich, S. B.; Gates, C. M.; Feldman, R. A.; Spudich, J. L.; Spudich, E. N.; DeLong, E. F. Science 2000, 289, 1902-6.

(2) Foster, K. W.; Saranak, J.; Patel, N.; Zarilli, G.; Okabe, M.; Kline, T.; Nakanishi, K. Nature 1984, 311, 756-759.

(3) Bieszke, J. A.; Braun, E. L.; Bean, L. E.; Kang, S.; Natvig, D. O.; Borkovich, K. A. Proc. Natl. Acad. Sci. U. S. A. 1999, 96, 8034-9.

(4) Finkel, O. M.; Beja, O.; Belkin, S. ISME J 2013, 7, 448-51.

(5) Man, D.; Wang, W.; Sabehi, G.; Aravind, L.; Post, A. F.; Massana, R.; Spudich, E. N.; Spudich, J. L.; Beja, O. EMBO J. 2003, 22, 1725-31.

(6) Beja, O.; Spudich, E. N.; Spudich, J. L.; Leclerc, M.; DeLong, E. F. Nature 2001, 411, 786-9.

(7) de la Torre, J. R.; Christianson, L. M.; Beja, O.; Suzuki, M. T.; Karl, D. M.; Heidelberg, J.; DeLong, E. F. Proc. Natl. Acad. Sci. U. S. A. 2003, 100, 12830-5.

(8) DeLong, E. F. Nature 2009, 459, 200-6.

(9) Gomez-Consarnau, L.; Akram, N.; Lindell, K.; Pedersen, A.; Neutze, R.; Milton, D. L.; Gonzalez, J. M.; Pinhassi, J. PLoS Biol. 2010, 8, e1000358.

(10) Friedrich, T.; Geibel, S.; Kalmbach, R.; Chizhov, I.; Ataka, K.; Heberle, J.; Engelhard, M.; Bamberg, E. J. Mol. Biol. 2002, 321, 821-38.

(11) Dioumaev, A. K.; Brown, L. S.; Shih, J.; Spudich, E. N.; Spudich, J. L.; Lanyi, J. K. Biochemistry 2002, 41, 5348-5358.

(12) Inoue, K.; Kato, Y.; Kandori, H. Trends Microbiol. 2015, 23, 91-8.

(13) Wang, W. W.; Sineshchekov, O. A.; Spudich, E. N.; Spudich, J. L. J. Biol. Chem. 2003, 278, 33985-91.

(14) Ran, T.; Ozorowski, G.; Gao, Y.; Sineshchekov, O. A.; Wang, W.; Spudich, J. L.; Luecke, H. Acta Crystallogr. D Biol. Crystallogr. 2013, 69, 1965-80.

(15) Maciejko, J.; Mehler, M.; Kaur, J.; Lieblein, T.; Morgner, N.; Ouari, O.; Tordo, P.; Becker-Baldus, J.; Glaubitz, C. J. Am. Chem. Soc. 2015, 137, 9032-43.

(16) Mors, K.; Roos, C.; Scholz, F.; Wachtveitl, J.; Dotsch, V.; Bernhard, F.; Glaubitz, C. Biochim. Biophys. Acta 2013, 1828, 1222-9.

(17) Bamann, C.; Bamberg, E.; Wachtveitl, J.; Glaubitz, C. Biochim. Biophys. Acta 2014, 1837, 614-25.

(18) Shi, L. C.; Ahmed, M. A. M.; Zhang, W. R.; Whited, G.; Brown, L. S.; Ladizhansky, V. J. Mol. Biol. 2009, 386, 1078-1093.

(19) Eckert, C. E.; Kaur, J.; Glaubitz, C.; Wachtveitl, J. J Phys Chem Lett 2017, 8, 512517.

(20) Reckel, S.; Gottstein, D.; Stehle, J.; Lohr, F.; Verhoefen, M. K.; Takeda, M.; Silvers, R.; Kainosho, M.; Glaubitz, C.; Wachtveitl, J.; Bernhard, F.; Schwalbe, H.; Guntert, P.; Dotsch, V. Angew. Chem. Int. Ed. Engl. 2011, 50, 11942-6.

(21) Yang, J.; Aslimovska, L.; Glaubitz, C. J. Am. Chem. Soc. 2011, 133, 4874-81.

(22) Lanyi, J. K. Mol. Membr. Biol. 2004, 21, 143-50.

(23) Bergo, V. B.; Sineshchekov, O. A.; Kralj, J. M.; Partha, R.; Spudich, E. N.; Rothschild, K. J.; Spudich, J. L. J. Biol. Chem. 2009, 284, 2836-43.

(24) Hempelmann, F.; Holper, S.; Verhoefen, M. K.; Woerner, A. C.; Kohler, T.; Fiedler, S. A.; Pfleger, N.; Wachtveitl, J.; Glaubitz, C. J. Am. Chem. Soc. 2011, 133, 4645-54.

(25) Bajaj, V. S.; Mak-Jurkauskas, M. L.; Belenky, M.; Herzfeld, J.; Griffin, R. G. Proc Natl Acad Sci U S A 2009, 106, 9244-9.

(26) Griffiths, J. M.; Bennett, A. E.; Engelhard, M.; Siebert, F.; Raap, J.; Lugtenburg, J.; Herzfeld, J.; Griffin, R. G. Biochemistry 2000, 39, 362-371.

(27) Lansing, J. C.; Hohwy, M.; Jaroniec, C. P.; Creemers, A. F. L.; Lugtenburg, J.; Herzfeld, J.; Griffin, R. G. Biochemistry 2002, 41, 431-438.

(28) Smith, S. O.; Courtin, J.; Van den Berg, E.; Winkel, C.; Lugtenburg, J.; Herzfeld, J.; Griffin, R. G. Biochemistry 1989, 28, 237-243. 
(29) Hu, J. G.; Sun, B. Q.; Bizounok, M.; Hatcher, M. E.; Lansing, J. C.; Raap, J.; Verdegem, P. J.; Lugtenburg, J.; Griffin, R. G.; Herzfeld, J. Biochemistry 1998, 37, 8088-96.

(30) Thompson, L. K.; McDermott, A. E.; Raap, J.; van der Wielen, C. M.; Lugtenburg, J.; Herzfeld, J.; Griffin, R. G. Biochemistry 1992, 31, 7931-8.

(31) Becker-Baldus, J.; Bamann, C.; Saxena, K.; Gustmann, H.; Brown, L. J.; Brown, R. C.; Reiter, C.; Bamberg, E.; Wachtveitl, J.; Schwalbe, H.; Glaubitz, C. Proc. Natl. Acad. Sci. U. S. A. 2015, 112, 9896-901.

(32) Mao, J.; Do, N. N.; Scholz, F.; Reggie, L.; Mehler, M.; Lakatos, A.; Ong, Y. S.; Ullrich, S. J.; Brown, L. J.; Brown, R. C.; Becker-Baldus, J.; Wachtveitl, J.; Glaubitz, C. J. Am. Chem. Soc. 2014, 136, 17578-90.

(33) Mehler, M.; Scholz, F.; Ullrich, S. J.; Mao, J.; Braun, M.; Brown, L. J.; Brown, R. C.; Fiedler, S. A.; Becker-Baldus, J.; Wachtveitl, J.; Glaubitz, C. Biophys. J. 2013, 105, 385-97.

(34) Etzkorn, M.; Seidel, K.; Li, L.; Martell, S.; Geyer, M.; Engelhard, M.; Baldus, M. Structure 2010, 18, 293-300.

(35) Concistre, M.; Gansmuller, A.; McLean, N.; Johannessen, O. G.; Marin Montesinos, I.; Bovee-Geurts, P. H.; Verdegem, P.; Lugtenburg, J.; Brown, R. C.; DeGrip, W. J.; Levitt, M. H. J. Am. Chem. Soc. 2008, 130, 10490-1.

(36) Kimata, N.; Pope, A.; Eilers, M.; Opefi, C. A.; Ziliox, M.; Hirshfeld, A.; Zaitseva, E.; Vogel, R.; Sheves, M.; Reeves, P. J.; Smith, S. O. Nat. Commun. 2016, 7, 12683.

(37) Yomoda, H.; Makino, Y.; Tomonaga, Y.; Hidaka, T.; Kawamura, I.; Okitsu, T.; Wada, A.; Sudo, Y.; Naito, A. Angew. Chem. Int. Ed. Engl. 2014, 53, 6960-4.

(38) Rosay, M.; Lansing, J. C.; Haddad, K. C.; Bachovchin, W. W.; Herzfeld, J.; Temkin, R. J.; Griffin, R. G. J. Am. Chem. Soc. 2003, 125, 13626-7.

(39) Ni, Q. Z.; Daviso, E.; Can, T. V.; Markhasin, E.; Jawla, S. K.; Swager, T. M.; Temkin, R. J.; Herzfeld, J.; Griffin, R. G. Acc. Chem. Res. 2013, 46, 1933-41.

(40) Sauvee, C.; Rosay, M.; Casano, G.; Aussenac, F.; Weber, R. T.; Ouari, O.; Tordo, P. Angew. Chem. Int. Ed. Engl. 2013, 52, 10858-61.

(41) Hong, M. J. Magn. Reson. 1999, 136, 86-91.

(42) Szeverenyi, N. M.; Sullivan, M. J.; Maciel, G. E. J. Magn. Reson. 1982, 47, 462-475.

(43) Feng, X.; Lee, Y. K.; Sandstrom, D.; Eden, M.; Maisel, H.; Sebald, A.; Levitt, M. H. Chem. Phys. Lett. 1996, 257, 314-320.

(44) Wickstrand, C.; Dods, R.; Royant, A.; Neutze, R. Biochim. Biophys. Acta 2015, 1850, 536-53.

(45) Harbison, G. S.; Mulder, P. P. J.; Pardoen, H.; Lugtenburg, J.; Herzfeld, J.; Griffin, R. G. J. Am. Chem. Soc. 1985, 107, 4809-4816.

(46) Englert, G. Helv. Chim. Acta 1975, 58, 2367-90.

(47) Inoue, Y.; Tokito, Y.; Tomonoh, S.; Chujo, R. Bull. Chem. Soc. Jpn. 1979, 52, 265-

266 .

(48) Andersson, M.; Malmerberg, E.; Westenhoff, S.; Katona, G.; Cammarata, M.; Wohri, A. B.; Johansson, L. C.; Ewald, F.; Eklund, M.; Wulff, M.; Davidsson, J.; Neutze, R. Structure 2009, 17, 1265-75.

(49) Mak-Jurkauskas, M. L.; Bajaj, V. S.; Hornstein, M. K.; Belenky, M.; Griffin, R. G.; Herzfeld, J. Proc. Natl. Acad. Sci. U. S. A. 2008, 105, 883-8.

(50) Balashov, S. P.; Imasheva, E. S.; Boichenko, V. A.; Anton, J.; Wang, J. M.; Lanyi, J. K. Science 2005, 309, 2061-4.

(51) Miranda, M. R.; Choi, A. R.; Shi, L.; Bezerra, A. G., Jr.; Jung, K. H.; Brown, L. S. Biophys. J. 2009, 96, 1471-81.

(52) Brown, L. S.; Dioumaev, A. K.; Lanyi, J. K.; Spudich, E. N.; Spudich, J. L. J. Biol. Chem. 2001, 276, 32495-505.

(53) Fan, Y.; Shi, L.; Brown, L. S. FEBS Lett. 2007, 581, 2557-61.

(54) Fuhrman Jed A. , S. M. S.; Ulrich, S. Nat. Rev. Microbiol. 2008, 488-494.

(55) Gomez-Consarnau, L.; Gonzalez, J. M.; Riedel, T.; Jaenicke, S.; Wagner-Dobler, I.; Sanudo-Wilhelmy, S. A.; Fuhrman, J. A. ISME J 2016, 10, 1102-12.

(56) Palovaara, J.; Akram, N.; Baltar, F.; Bunse, C.; Forsberg, J.; Pedros-Alio, C.; Gonzalez, J. M.; Pinhassi, J. Proc. Natl. Acad. Sci. U. S. A. 2014, 111, E3650-8. 
(57) Sabehi, G.; Beja, O.; Suzuki, M. T.; Preston, C. M.; DeLong, E. F. Environ. Microbiol. 2004, 6, 903-10.

(58) Varo, G.; Brown, L. S.; Lakatos, M.; Lanyi, J. K. Biophys. J. 2003, 84, 1202-7.

(59) Herzfeld, J.; Lansing, J. C. Annu. Rev. Biophys. Biomol. Struct. 2002, 31, 73-95.

(60) Leeder, A. J.; Brown, L. J.; Becker-Baldus, J.; Mehler, M.; Glaubitz, C.; Brown, R. C. D. submitted 2017.

(61) Fung, B. M.; Khitrin, A. K.; Ermolaev, K. J. Magn. Reson. 2000, 142, 97-101.

(62) Hohwy, M.; Jakobsen, H. J.; Eden, M.; Levitt, M. H.; Nielsen, N. C. J. Chem. Phys. 1998, 108, 2686-2694.

(63) Jaroniec, C. P.; Filip, C.; Griffin, R. G. J. Am. Chem. Soc. 2002, 124, 10728-10742.

(64) Concistre, M.; Johannessen, O. G.; McLean, N.; Bovee-Geurts, P. H.; Brown, R. C.; Degrip, W. J.; Levitt, M. H. J. Biomol. NMR 2012, 53, 247-56.

(65) Vinogradov, E.; Madhu, P. K.; Vega, S. Chem. Phys. Lett. 1999, 314, 443-450.

(66) Bak, M.; Rasmussen, J. T.; Nielsen, N. C. J. Magn. Reson. 2000, 147, 296-330.

(67) Slavov, C.; Hartmann, H.; Wachtveitl, J. Anal. Chem. 2015, 87, 2328-36.

(68) van Stokkum, I. H.; Larsen, D. S.; van Grondelle, R. Biochim. Biophys. Acta 2004, $1657,82-104$. 


\section{TOC Graphic}

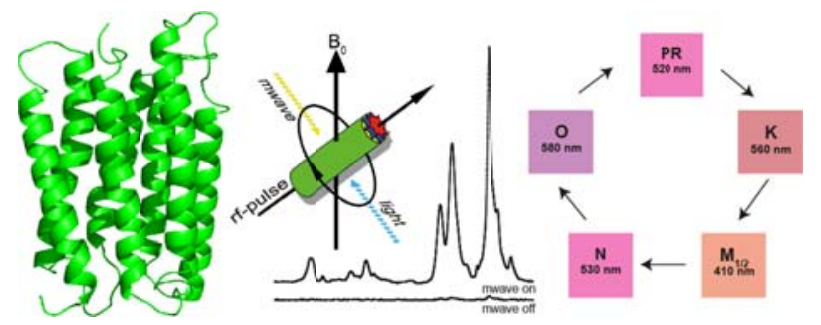

